\title{
OPTIMIZATION AND VALIDATION OF RP-HPLC/UV DETECTION FOR SEVERAL COMPOUNDS SIMULTANEOUSLY IN SEMI-PURIFIED EXTRACT OF WHITE TEA
}

\author{
Shaum Shiyan ${ }^{1,2}$, Triana Hertiani ${ }^{1}$, Ronny Martien ${ }^{1}$ and Akhmad Kharis \\ Nugroho ${ }^{1, *}$ \\ ${ }^{1}$ Faculty of Pharmacy, Universitas Gadjah Mada, Sekip Utara Yogyakarta Indonesia, 55281 \\ ${ }^{2}$ Department of Pharmacy, Faculty of Mathematics and Natural Sciences, Universitas Sriwijaya, \\ Indralaya (OI) Sumatera Selatan Indonesia, 30662 \\ *E-mail: a.k.nugroho@ugm.ac.id
}

\begin{abstract}
Modification of separation, detection, and quantification of several compounds simultaneously in white tea leaf extract using HPLC aims to obtain easy, fast, precise, and accurate analysis procedures. An HPLC optimization strategy was devised that allowed simultaneous determination of the effectiveness of separation and quantification of gallic acid, theobromine, theophylline, catechin, caffeine and epigallocatechin gallate. The compounds were separated and isocratically on a LiChrocart-C18 column. The optimal conditions for separation were determined using central composite design (CCD) with a solvent consisting of acetonitrile: methanol: $0.005 \%$ orthophosphoric acid $(10: 10: 80 \mathrm{v} / \mathrm{v} / \mathrm{v})$ at a $0.90 \mathrm{~mL} / \mathrm{min}$ flow rate. Validation procedures for modified analysis methods have been carried out following the terms and conditions. All validation points meet the requirements set by the International Council for Harmonization of Technical Requirements for Pharmaceuticals for Human Use. The validation results were successfully applied to a white tea leaf extract. CCD is very effective for HPLC system optimization and was efficient for the simultaneous analysis of several compounds in white tea extract.

Keywords: Optimization, Central Composite Design, Validation, HPLC, White Tea, EGCG.
\end{abstract}

(C) RASĀYAN. All rights reserved

\section{INTRODUCTION}

White tea is a product derived from the buds of Camellia sinensis L. leaves, this part which contains many polyphenol compounds. In Indonesia, white tea is widely produced on the island of Java and Sumatera. White tea leaves are processed quickly after harvest by a short drying period to avoid enzymatic oxidation of these compounds. The main polyphenols in these natural resources include epigallocatechin gallate (EGCG) and catechin (C) derivatives ${ }^{1}$. Tea leaves also contain several purine alkaloid compounds ${ }^{2}$, such as caffeine (CAF), theobromine (TB), and theophylline (TP). Phenolic and purine alkaloids in tea leaves have pharmacological effects ${ }^{3,4}$, and extracts from white tea leaves have antioxidant $^{5}$, antidiabetic ${ }^{6,7}$, and neuroprotective ${ }^{8}$ activities. In vitro and in vivo test results indicate that both white tea and EGCG have good activity as oxidative stress inhibitors ${ }^{9}$.

General analytical methods have been widely reported for the quantitative analysis of phenolic, flavonoid, and alkaloids in tea samples. However, the spectroscopic techniques used previously do not allow simultaneous separation of each compound. Methods previously reported for the analysis of some compounds in tea leaves include high-performance thin layer chromatography ${ }^{10}$, liquid chromatographymass spectrophotometry ${ }^{11,12}$, high-performance liquid chromatography ${ }^{13}$, electrochemical detection ${ }^{14}$, ultrafast liquid chromatography ${ }^{15,16}$, nuclear magnetic resonance spectroscopy ${ }^{10}$, and Fourier transform infrared spectroscopy ${ }^{17,18}$. In general, chromatographic-based techniques are more appropriate for the analysis of phenolic and purine alkaloids as they also allow separation of each compound.

Rasayan J. Chem., 12(3), 1098-1109(2019)

http://dx.doi.org/10.31788/RJC.2019.1235276

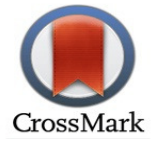


Development of an effective and beneficial method for the simultaneous analysis of several compounds in white tea leaf extracts remains a research challenge. In the routine analysis, a cost-effective, simple, easy and fast method is required but provides precise and accurate results. Some of the reported chromatographic separations have several disadvantages and some reported methods provide incomplete separation of compounds of interest ${ }^{12,19}$. Problems with C18 column separations include long run times, the chemical and structural complexities of phenolic and purine alkaloids, poor resolution of the compounds of interest, and the need for complex solvent mixtures for applications involving industrial extracts $^{20}$. The mobile phase composition and flow rate are the factors that determine the separation of compounds in the HPLC system ${ }^{21}$. Therefore, current research efforts are aimed at overcoming these shortcomings by optimizing the mobile phases and flow rates.

The design of experiments (DoE) approach is an application of simple statistics that can be used to obtain optimal HPLC conditions ${ }^{22,23}$. Several studies have conducted relating to DoE for tea leaf analysis, but the use of the DoE approach has been limited to optimization of the tea leaf extraction process ${ }^{24,25}$. One suitable design in the DoE approach for complicated process optimization is the central composite design (CCD). As far as our scientific knowledge, no study has yet examined the use of CCD to determine the optimal conditions of the HPLC system in simultaneous analysis of gallic acid (GA), TB, TP, CAF, C, and EGCG in a white tea extract. Determining the optimal condition of the HPLC system for the separation of six compounds using the CCD approach is one of the objectives of this study. An optimal separation was obtained using an isocratic system with a LiChrocart-C18 column and a solvent of acetonitrile, methanol, and $0.005 \%$ ortho-phosphoric acid an optimum flow rate. To obtain accurate and precise separation methods, validation is required to be accepted by health authorities, industries, and laboratories.

\section{Chemicals and Samples}

\section{EXPERIMENTAL}

The standard epigallocatechin gallate, catechin, gallic acid, theophylline, and theobromine used as references acquired from Sigma-Aldrich (St. Louis, MO, USA). Caffeine and ortho-phosphoric acid were obtained from Merck (Darmstadt, Germany). The solvent acetonitrile and methanol (HPLC-grade) were achieved from Fisher Scientific (Loughborough, Leics, UK). All eluents were purified using a $0.45 \mathrm{~mm}$ membrane from Millipore (Bedford, USA). White tea product from Camellia sinensis L. acquired from the Research Institute of Tea and Cinchona (RITC) Gamboeng, Jawa Barat, and Mitra Kerinci, Sumatera Barat, Indonesia.

\section{HPLC Instrumentation}

The HPLC instrument Hitachi series 2000 (Hitachi, Japan) equipped with an injection valve pump L-2130 with a $20 \mathrm{uL}$ loop volume was used. The system also included a detector of UV-Vis L-2420 (Hitachi, Japan) take action at $280 \mathrm{~nm}$. The results of the separation, both qualitative and quantitative data were processed and displayed using D-2000 Elite software. The separation was carried out on a reversed-phase C18 column using LiChrocart-C18 $(250 \times 4.6 \mathrm{~mm}$ i.d.; $5 \mu \mathrm{m})$ with a guard column were acquired from Merck (Darmstadt, Germany).

\section{Optimization Method Using CCD}

A CCD was applied to optimize the analytical method development using HPLC. The factors (independent variables) studied for the analytical method development were: the ratio of acetonitrile (\%, $\left.\mathrm{X}_{1}\right)$, methanol $\left(\%, \mathrm{X}_{2}\right)$ and flow rate $\left(\mathrm{mL} / \mathrm{min}, \mathrm{X}_{3}\right)$. Experimental design of analytical methods is presented in Table-1. Verification of the optimum conditions was evaluated by injecting a standard mixture on the HPLC system by six replications. The data obtained were tested statistically by comparing the optimum value of the predicted result using one sample t-test.

\section{System Suitability Test}

The mixed solutions of GA, TB, TP, CAF, C, and EGCG were prepared. The standard mixture was included in the HPLC instrumentation with six replications. The retention time (tR), resolution (Rs), theoretical plates (N), tailing factor (Tf) and peak area are recorded and observed. The system suitability 
RASĀYAN J. Chem.

Vol. 12 | No. 3 |1098 - 1109| July - September | 2019

test was measured by reference to precision parameters; the critical value in this test is based on percent relative standard deviation $(\mathrm{RSD})^{26}$. The $\% \mathrm{RSD}$ values should not be more than $2 \%$.

Table-1: Completely CCD and the HPLC Condition Experimental Results

\begin{tabular}{|c|c|c|c|c|c|c|c|c|c|c|c|c|}
\hline \multirow[t]{2}{*}{ Run } & \multicolumn{3}{|c|}{$\begin{array}{l}\text { Factors on the } \\
\text { System }\left(X_{n}\right)\end{array}$} & \multicolumn{9}{|c|}{ Response $\left(Y_{n}\right)$} \\
\hline & $\mathrm{X}_{1}$ & $\mathrm{X}_{2}$ & $\mathrm{X}_{3}$ & $\mathrm{Y}_{1}$ & $\mathrm{Y}_{2}$ & $\mathrm{Y}_{3}$ & $\mathrm{Y}_{4}$ & $\mathrm{Y}_{5}$ & $\mathrm{Y}_{6}$ & $Y_{7}$ & $\mathrm{Y}_{8}$ & $\mathrm{Y}_{9}$ \\
\hline 1 & 9.00 & 9.00 & 1.00 & 18.74 & 4353 & 3650 & 2.37 & 6.38 & 1.76 & 7.95 & 1.51 & 547265 \\
\hline 2 & 10.00 & 11.00 & 0.75 & 18.12 & 5097 & 3659 & 1.72 & 5.1 & 2.16 & 5.51 & 1.64 & 677763 \\
\hline 3 & 9.00 & 13.00 & 1.00 & 13.06 & 3777 & 2976 & 1.68 & 4.02 & 2.52 & 4.36 & 1.6 & 647601 \\
\hline 4 & 10.00 & 11.00 & 1.25 & 10.93 & 3806 & 3028 & 1.53 & 4.59 & 2.01 & 5.04 & 1.55 & 451152 \\
\hline 5 & 9.00 & 9.00 & 0.50 & 31.43 & 5968 & 4613 & 2.11 & 7.03 & 1.83 & 8.02 & 1.68 & 1176023 \\
\hline 6 & 8.00 & 7.00 & 1.25 & 25.57 & 4705 & 3809 & 3.43 & 8.38 & 1.27 & 10.64 & 1.47 & 379312 \\
\hline 7 & 9.00 & 9.00 & 1.50 & 13.47 & 3629 & 2969 & 2.03 & 5.90 & 1.44 & 7.23 & 1.48 & 415548 \\
\hline 8 & 10.00 & 7.00 & 0.75 & 26.51 & 5582 & 4228 & 2.44 & 8.07 & 1.17 & 9.37 & 1.62 & 671108 \\
\hline 9 & 10.00 & 7.00 & 1.25 & 15.51 & 4311 & 3419 & 2.08 & 6.87 & 1.18 & 8.12 & 1.55 & 389237 \\
\hline 10 & 9.00 & 9.00 & 1.00 & 19.16 & 4756 & 3686 & 2.42 & 6.49 & 1.95 & 7.83 & 1.62 & 548145 \\
\hline 11 & 8.00 & 11.00 & 0.75 & 25.67 & 5278 & 3911 & 2.77 & 6.42 & 2.49 & 7.73 & 1.59 & 637998 \\
\hline 12 & 9.00 & 5.00 & 1.00 & 31.50 & 4723 & 3958 & 3.29 & 6.59 & 0.64 & 8.33 & 1.58 & 555992 \\
\hline 13 & 9.00 & 9.00 & 1.00 & 19.63 & 4410 & 3540 & 2.3 & 6.50 & 1.66 & 7.85 & 1.55 & 620200 \\
\hline 14 & 7.00 & 9.00 & 1.00 & 31.14 & 4589 & 4120 & 3.85 & 7.88 & 1.90 & 10.54 & 1.39 & 477663 \\
\hline 15 & 8.00 & 7.00 & 0.75 & 43.78 & 6064 & 4820 & 4.00 & 9.66 & 1.37 & 12.16 & 1.5 & 562638 \\
\hline 16 & 9.00 & 9.00 & 1.00 & 18.81 & 4706 & 3721 & 2.43 & 6.57 & 1.86 & 7.99 & 1.52 & 546714 \\
\hline 17 & 9.00 & 9.00 & 1.00 & 20.01 & 4373 & 3661 & 2.31 & 6.49 & 1.68 & 7.97 & 1.53 & 623882 \\
\hline 18 & 9.00 & 9.00 & 1.00 & 19.32 & 4672 & 3535 & 2.38 & 6.65 & 1.78 & 7.9 & 1.59 & 570289 \\
\hline 19 & 8.00 & 11.00 & 1.25 & 15.49 & 4061 & 3069 & 2.38 & 5.37 & 2.38 & 6.49 & 1.59 & 414440 \\
\hline 20 & 11.00 & 9.00 & 1.00 & 13.40 & 4049 & 3237 & 1.41 & 5.04 & 1.71 & 5.42 & 1.62 & 604139 \\
\hline
\end{tabular}

\section{Selectivity Test}

The white tea extract solution and the standard solution mixture prepared with GA, TB, TP, CAF, C, and EGCG concentrations were 2, 5, 5, 5, 10, and $25 \mu \mathrm{g} / \mathrm{mL}$, respectively. White tea extract solution and standard solution mixture were analyzed by HPLC. The selectivity is good when the resolution value (Rs) $\geq 1.5^{27}$.

\section{Linearity and Sensitivity Test}

The mixtures of GA, TB, TP, CAF, C, and EGCG solutions were prepared with seven different concentration levels. Measurements were carried out in each series of concentrations in the HPLC instrumentation that had been conditioned. Concentration data and peak obtained by calculation of intercept value (a), slope (b) and correlation coefficient $\left(r^{2}\right)$. The analytical method is called good to have good linearity if the value of $r^{2} \geq 0.999^{28}$. The standard curve parameters that include $\mathrm{a}, \mathrm{b}$, and $r^{2}$ were determined using the least square linear regression analysis with the help of Microsoft Excel software.

\section{Limit of Detection (LoD) and Limit of Quantification (LoQ)}

The LoD and LoQ parameters were evaluated based on the residual standard deviation of the regression line response (r) the measured catechin concentration series and slope of the calibration curve $(\mathrm{S})^{29}$. The LoD value follows the equation $3.3 \mathrm{r} / \mathrm{S}$, and $\mathrm{LoQ}$ is $10 \mathrm{r} / \mathrm{S}$.

\section{Precision and Accuracy}

The catechin standard was added to the sample $(50 \mu \mathrm{g} / \mathrm{mL})$ and the standard solution mixed was taken from three points on the standard curve, namely 4, 5, and $6 \mu \mathrm{g} / \mathrm{mL}$. Analyses were performed in three replications. Precision analytical methods are eligible if RSD testing is nothing more than RSD Horwitz $^{27,30}$. The accuracy of the HPLC analysis method in this study used additional standard, by adding GA, TB, TP, CAF, C, and EGCG to the extract. The analytical method is eligible if the recovery of the determination result is in the range of acceptability. 
RASĀYAN J. Chem.

Vol. 12 | No. 3 |1098 - 1109| July - September | 2019

\section{Robustness}

Robustness can be evaluated statistically from $\operatorname{DoE}^{22}$. The robustness parameter was assessed from the surface response, and all the responses from the factors on the CCD were 20 experiments $^{31}$.

\section{Analysis of White Tea Extract Sample}

A number of purified white tea extract is weighed more or less $10 \mathrm{mg}$ and put into a $10 \mathrm{~mL}$ flask. A total of approximately $10 \mathrm{~mL}$ of eluent was mixed using an ultrasonicator for 5 minutes. The sample was diluted with a mobile phase to produce an analyte mixture in a solvent of $75 \mu \mathrm{g} / \mathrm{mL}$. The sample solution was purified with a $0.45 \mu \mathrm{m}$ membrane for further analysis with HPLC. The validated calibration curve was used to calculate the content of GA, TB, TP, CAF, C, and EGCG in the sample. The final content of each compound was expressed in percent (\%).

\section{Statistical Analysis}

The HPLC system optimization data were evaluated using Design-Expert software (Stat-Ease Inc, Minneapolis, USA). Statistical analysis was performed using analysis of variance (ANOVA). The data were statistically analyzed with the help SPSS software (SPSS Inc, Chicago, USA). The significance value in the data analysis determined $p<0.05$.

\section{RESULTS AND DISCUSSION \\ Optimization of HPLC Condition Using CCD Model Analysis}

The CCD experimental design was performed using 20 experimental runs (Table-1). The independent variables were the acetonitrile $\left(\mathrm{X}_{1}\right)$, methanol $\left(\mathrm{X}_{2}\right)$, and the flow rate $\left(\mathrm{X}_{3}\right)$; the dependent variables were the total retention time $\left(\mathrm{Y}_{1}\right)$, the theoretical plates of $\mathrm{C}\left(\mathrm{Y}_{2}\right)$, the theoretical plates of EGCG $\left(\mathrm{Y}_{3}\right)$, the resolution of GA-TB $\left(\mathrm{Y}_{4}\right)$, the resolution of TP-C $\left(\mathrm{Y}_{5}\right)$, the resolution of $\mathrm{C}-\mathrm{CAF}\left(\mathrm{Y}_{6}\right)$, the resolution of CAF-EGCG $\left(\mathrm{Y}_{7}\right)$, the tailing factor of EGCG $\left(\mathrm{Y}_{8}\right)$, and the peak area of EGCG $\left(\mathrm{Y}_{9}\right)$. An approach using DoE, the best model selection is based on several important criteria. The criteria include, the model is significant $(p<0.05)$, lack of fit has a non-significant value $(p>0.05)$, the coefficients of determination $\left(\mathrm{R}^{2}\right)$ should be above 0.7 and the difference in value between adjusted $R^{2}$ (Adj. $R^{2}$ ) and predicted $R^{2}$ (Pred. $R^{2}$ ) below $0.2^{32,33}$.

The overall response (Y) provides a significant model. In theory, the lack of fit ideally gives not significant results. However, in the assessment of lack of fit, the difference from Adj. $\mathrm{R}^{2}$ and Pred. $\mathrm{R}^{2}$ is a special consideration. If the resulting difference is below 0.2 and $\mathrm{R}^{2}$ above 0.7 , the model obtained can be used to predict optimal conditions. Differences Predicted $\mathrm{R}^{2}$ and Adjusted $\mathrm{R}^{2}$ for all responses below 0.2 (Table-2). Adequate precision is used to determine the ratio of signals to noise. All model obtained have a ratio of more than 4 . Based on statistical data obtained in Table-2, the overall equation model meets the requirements to be used in predicting optimal conditions.

The least squares regression is used in estimating the coefficient value on the model. A positive sign shows a favorable response. The inverse correlation between factors $(\mathrm{X})$ and responses $(\mathrm{Y})$ is indicated by a negative value. The model transformation was carried out at $Y_{1}$ and $Y_{9}$ to explain accurately strong interaction. The inverse model means that a high coefficient value reduces the main effect (interaction) and vice versa. The relative effect of factors is evaluated from the code equation by comparing the $\mathrm{R}^{2}$ value. The fitting result equation model proposed for nine responses is presented in Table-3.

Factors $\mathrm{X}_{1}, \mathrm{X}_{2}$, and $\mathrm{X}_{3}$ contributed significantly to the overall model equation with $p<0.05\left(\mathrm{Y}_{1}, \mathrm{Y}_{2}, \mathrm{Y}_{3}\right.$, $\mathrm{Y}_{4}, \mathrm{Y}_{5}, \mathrm{Y}_{6}, \mathrm{Y}_{7}, \mathrm{Y}_{8}$, and $\mathrm{Y}_{9}$ ). However, no significant status was found for the lack of fit parameters, namely in the $\mathrm{Y}_{4}, \mathrm{Y}_{5}$, and $\mathrm{Y}_{7}$ responses. The actual and predicted response variable plot for the total retention time, the theoretical plates of EGCG, the resolution of C-CAF and the peak area of EGCG (Fig.-1) reveals the good closeness between the predicted and experimental results. Similarly, for response variables GA-TB, TP-C, and CAF-EGCG, although the value of lack of fit is significant. As observed, all of the actual response point variables are quite close to their predictive value, indicating that the model is strong and accurate.

It is clear from the equation that the factor of the acetonitrile, methanol and flow rate ratios have a positive effect on the total retention time factor. The 3D surface response contour plot is presented as 
RASĀYAN J. Chem.

Vol. 12 | No. 3 |1098 - 1109| July - September | 2019

Fig.-2 which is very useful for studying the interaction effects of factors on the response. The relationship between the response factor and the independent factor is linear, whereas in case the $Y_{3}$ and $Y_{4}$ response factor are squared (Table-3). The ratio of acetonitrile, methanol and flow rate is optimized to obtain the separation of GA, TB, TP, CAF, C, and EGCG with good resolution results (Fig.-4a). These compounds were eluted at $3.68,4.14,5.70,7.90,8.91$, and 13.18 minutes.

Table-2: Evaluation Parameters of the Response Equation Model From CCD

\begin{tabular}{c|c|c|c|c|c|c|c|c|c|c}
\hline & $\begin{array}{c}\text { Std. } \\
\text { Dev. }\end{array}$ & Mean & $\% \mathrm{CV}$ & Press & $\mathrm{R}^{2}$ & $\begin{array}{c}\text { Adj. } \\
\mathrm{R}^{2}\end{array}$ & $\begin{array}{c}\text { Pred. } \\
\mathrm{R}^{2}\end{array}$ & $\begin{array}{c}\text { Adeq. } \\
\text { Precision }\end{array}$ & Model & Lack of Fit \\
\hline $\mathrm{Y}_{1}$ & 0.0048 & 0.2255 & 2.14 & 0.0006 & 0.9874 & 0.9851 & 0.9791 & 68.5262 & Significant & Not significant \\
\hline $\mathrm{Y}_{2}$ & 279.12 & 4645.45 & 6.01 & $\begin{array}{c}219100 \\
000\end{array}$ & 0.8582 & 0.8316 & 0.7506 & 19.6593 & Significant & Not significant \\
\hline $\mathrm{Y}_{3}$ & 107.34 & 3680.45 & 2.92 & $\begin{array}{c}735100 \\
00\end{array}$ & 0.9766 & 0.9555 & 0.8506 & 23.7942 & Significant & Not significant \\
\hline $\mathrm{Y}_{4}$ & 0.1553 & 2.45 & 6.35 & 1.87 & 0.9751 & 0.9526 & 0.8071 & 22.0631 & Significant & Significant \\
\hline $\mathrm{Y}_{5}$ & 0.6474 & 6.50 & 9.96 & 12.87 & 0.8021 & 0.7650 & 0.6204 & 14.6015 & Significant & Significant \\
\hline $\mathrm{Y}_{6}$ & 0.1177 & 1.74 & 6.77 & 0.3698 & 0.9476 & 0.9378 & 0.9126 & 37.0854 & Significant & Not significant \\
\hline $\mathrm{Y}_{7}$ & 0.7982 & 7.82 & 10.20 & 19.61 & 0.8543 & 0.8270 & 0.7198 & 17.0672 & Significant & Significant \\
\hline $\mathrm{Y}_{8}$ & 0.0462 & 1.56 & 2.97 & 0.0572 & 0.6138 & 0.5414 & 0.3541 & 9.2483 & Significant & Not significant \\
\hline $\mathrm{Y}_{9}$ & 0.0002 & 0.002 & 10.20 & 0.0000 & 0.8410 & 0.8112 & 0.7328 & 19.6933 & Significant & Not significant \\
\hline
\end{tabular}

A Predicted vs actual

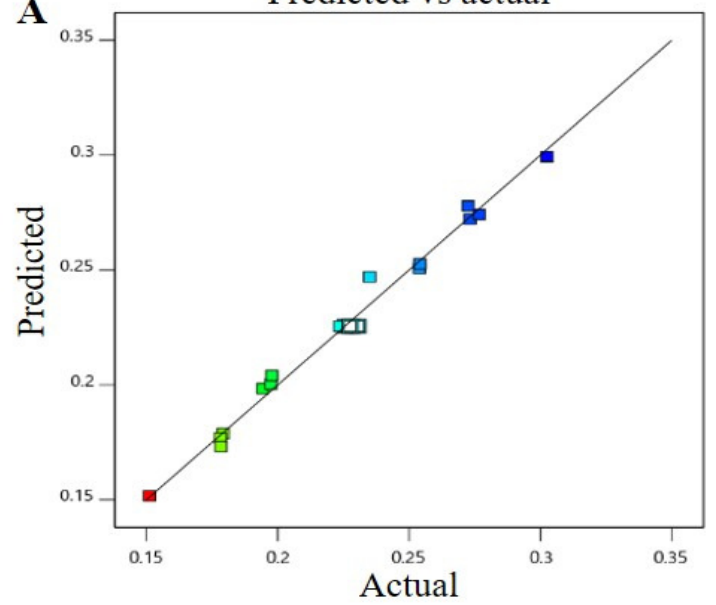

C

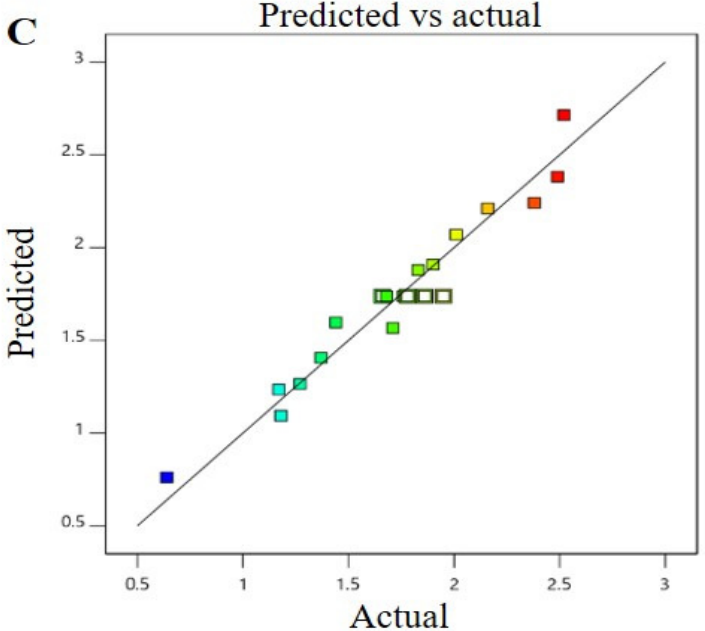

B

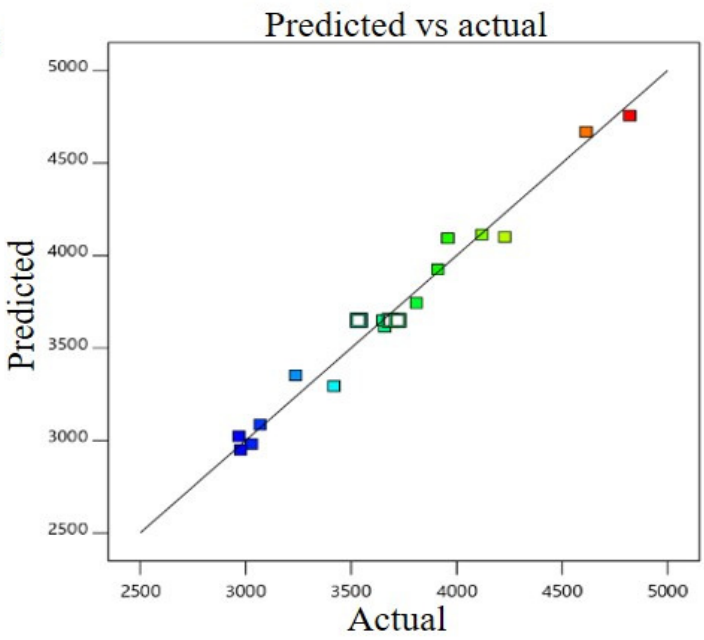

D

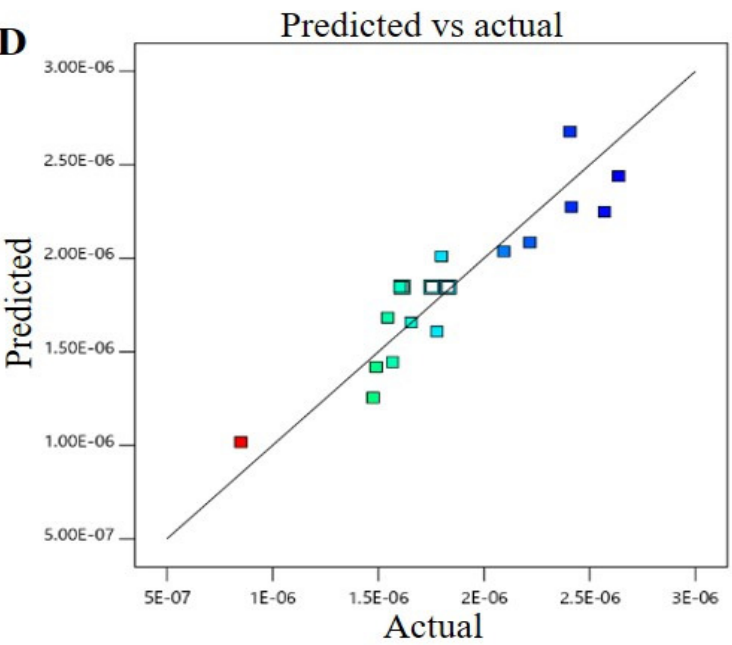

Fig.-1: Actual Values and Predicted Results Calculated from the Polynomial Equation for the Total Retention Time (A), the Theoretical Plates of EGCG (B), the Resolution of C-CAF (C), and the Peak Area of EGCG (D) 
RASĀYAN J. Chem.

Vol. 12 | No. 3 |1098 - 1109| July - September | 2019
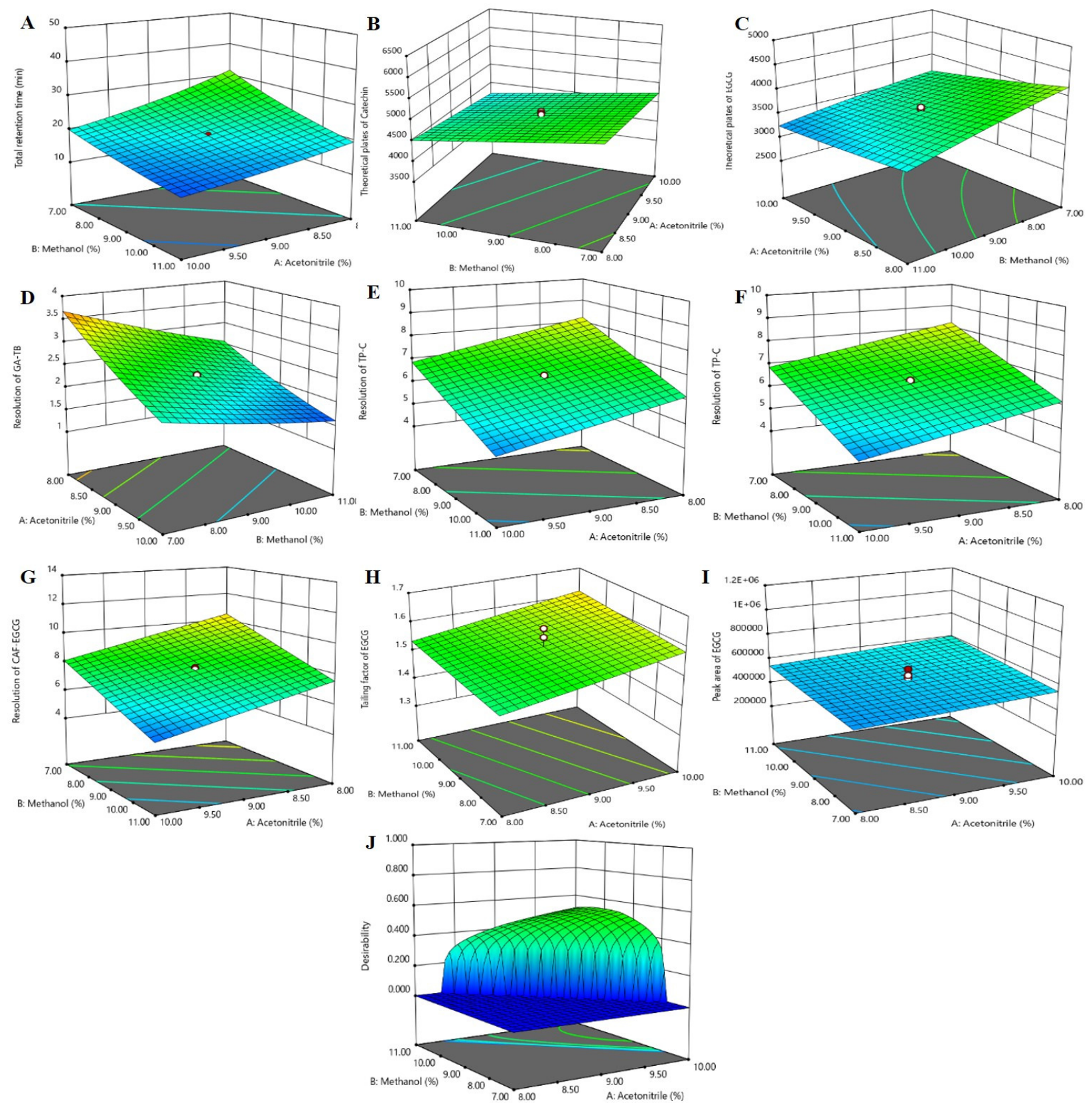

Fig.-2: Response Surface Plots (3D) for the Total Retention Time (A), Theoretical Plates of Catechin (B),

Theoretical Plates of EGCG (C), the Resolution of GA-TB (D), the Resolution of TP-C (E), the Resolution of C-

CAF (F), the Resolution of CAF-EGCG $(\mathrm{G})$, the Tailing Factor of EGCG $(\mathrm{H})$, the Peak Area of EGCG (I) and

Desirability (J)

\section{Verification of Optimum Conditions and Suitability Test (SST)}

The verification of optimum conditions and SST was performed before the validation process. Based on the one sample t-test, only the resolution of $\mathrm{C}-\mathrm{CAF}$ with result $p<0.05(0.000)$, others parameter $p>0.05$. Although statistically unverified, the compounds $\mathrm{C}$ and CAF are well separated. Average value $(n=6)$ of the resolution of $\mathrm{C}-\mathrm{CAF} 1.83$ (good resolution required more than 1.5). The total retention time $(n=6)$ averaged 15.89 minutes from the optimum prediction of 15.90 minutes $(p>0.05)$. The resolution of GATB $(n=6)$ averaged 1.74 of the $1.74(p>0.05)$ predictions. The theoretical plates of $\mathrm{C}(n=6)$ averaged 4702 from 4602 predictions $(p>0.05)$. The theoretical plates of EGCG $(n=6)$ averaged 3458 of the predicted $3513(p>0.05)$. The tailings factor of EGCG $(n=6)$ averaged 3458 of the 3513 predictions and the peak area of EGCG $(n=6)$ averaged 23158 from 23742 predictions $(p>0.05)$. These results indicate the optimal conditions of HPLC systems acquired using DoE have been verified. 
RASĀYAN J. Chem.

Vol. 12 | No. 3 |1098 - 1109| July - September | 2019

Tabel-3: Models and Regression Equations for All Responses

\begin{tabular}{|c|c|c|c|}
\hline Response & Transform & Model & Regressed Equation \\
\hline $\mathrm{Y}_{1}$ & Inverse sqrt & Linear & $\frac{1}{\sqrt{\gamma_{1}}}=0.23 \mathrm{X}_{1}+0.024 \mathrm{X}_{2}+0.026 \mathrm{X}_{3}$ \\
\hline $\mathrm{Y}_{2}$ & None & Linear & $\mathrm{Y}_{2}=4645.45-149.50 \mathrm{X}_{1}-269.50 \mathrm{X}_{2}-613.50 \mathrm{X}_{3}$ \\
\hline $\mathrm{Y}_{3}$ & None & Quadratic & $\begin{array}{r}Y_{3}=3650.48-190.06 X_{1}-285.81 X_{2}-411.31 X_{3}+86.12 X_{1} X_{2}+ \\
51.62 X_{1} X_{3}+43.37 X_{2} X_{3}+20.74 X_{1}^{2}-32.14 X_{2}^{2}+48.86 X_{3}^{2}\end{array}$ \\
\hline $\mathrm{Y}_{4}$ & None & Quadratic & $\begin{array}{c}\mathrm{Y}_{4}=2.40-0.6056 \mathrm{X}_{1}-0.4231 \mathrm{X}_{2}-0.1044 \mathrm{X}_{3}+0.1263 \mathrm{X}_{1} \mathrm{X}_{2}+ \\
0.0512 \mathrm{X}_{1} \mathrm{X}_{3}+0.0437 \mathrm{X}_{2} \mathrm{X}_{3}+0.0795 \mathrm{X}_{1}^{2}+0.0433 \mathrm{X}_{2}^{2}+0.0605 \mathrm{X}_{3}^{2}\end{array}$ \\
\hline $\mathrm{Y}_{5}$ & None & Linear & $\mathrm{Y}_{5}=6.50-6.800 \mathrm{X}_{1}-1.04 \mathrm{X}_{2}-0.3937 \mathrm{X}_{3}$ \\
\hline $\mathrm{Y}_{6}$ & None & Linear & $Y_{6}=1.74-0.0856 X_{1}+0.4881 X_{2}-0.0706 X_{3}$ \\
\hline $\mathrm{Y}_{7}$ & None & Linear & $\mathrm{Y}_{7}=7.82-1.20 \mathrm{X}_{1}-1.47 \mathrm{X}_{2}-0.3787 \mathrm{X}$ \\
\hline $\mathrm{Y}_{8}$ & None & Linear & $\mathrm{Y}_{8}=1.56+0.0419 \mathrm{X}_{1}+0.0169 \mathrm{X}_{2}-0.0369 \mathrm{X}_{3}$ \\
\hline $\mathrm{Y}_{9}$ & Inverse & Linear & $1 / \mathrm{Y}_{8}=1.847 \mathrm{E}-06-9.496 \mathrm{E}-08 \mathrm{X}_{1}-8.184 \mathrm{E}-08 \mathrm{X}_{2}+4.148 \mathrm{E}-07 \mathrm{X}_{3}$ \\
\hline
\end{tabular}

The suitability test, RSD value is found to be less than $2 \%$ for all parameters tested $(0.22-1.99 ; n=6)$, the system suitability test data shown in Table-4. The RSD value for all test variables is less than $2 \%$ both for retention time, theoretical plates, resolution, tailing factor and peak area. The data obtained indicate that the HPLC system applied for the separation of GA, TB, TP, CAF, C, and EGCG is appropriate.

Table-4: System Suitability Test ( $n=6 ; *$ value of \% RSD)

\begin{tabular}{c|c|c|c|c|c}
\hline Compounds & $\begin{array}{c}\text { Retention time/ } \\
\text { RT (min) }\end{array}$ & $\begin{array}{c}\text { Theoretical } \\
\text { plates }\end{array}$ & Resolution & Tailing factor & $\begin{array}{c}\text { Peak area } \\
(\mathrm{mAU})\end{array}$ \\
\hline Gallic acid & $3.68 \pm 0.01 ;$ & $3482 \pm 58 ;$ & - & NA & $120502 \pm 2236 ;$ \\
& $0.22^{*}$ & $1.67^{*}$ & & & $1.86^{*}$ \\
\hline Theobromine & $4.14 \pm 0.01 ;$ & $3950 \pm 26 ;$ & $1.78 \pm 0.02 ;$ & $1.59 \pm 0.02 ;$ & $329006 \pm 5970 ;$ \\
& $0.29^{*}$ & $0.67^{*}$ & $0.87^{*}$ & $1.54^{*}$ & $1.81^{*}$ \\
\hline Theophylline & $5.70 \pm 0.02 ;$ & $4404 \pm 35 ;$ & $5.14 \pm 0.01 ;$ & $1.65 \pm 0.02 ;$ & $328797 \pm 5989 ;$ \\
& $0.29^{*}$ & $0.78^{*}$ & $0.29^{*}$ & $1.13^{*}$ & $1.82^{*}$ \\
\hline Catechin & $7.90 \pm 0.04 ;$ & $4330 \pm 86 ;$ & $5.36 \pm 0.05 ;$ & $1.51 \pm 0.03 ;$ & $225117 \pm 1478 ;$ \\
& $0.47^{*}$ & $1.99^{*}$ & $0.85^{*}$ & $1.66^{*}$ & $0.66^{*}$ \\
\hline Caffeine & $8.91 \pm 0.03 ;$ & $4464 \pm 44 ;$ & $2.00 \pm 0.02 ;$ & $1.63 \pm 0.02 ;$ & $291510 \pm 5362 ;$ \\
& $0.33^{*}$ & $0.99^{*}$ & $0.86^{*}$ & $1.31^{*}$ & $1.84^{*}$ \\
\hline EGCG & $13.18 \pm 0.11 ;$ & $3279 \pm 63 ;$ & $5.88 \pm 0.05 ;$ & $1.66 \pm 0.01 ;$ & $686148 \pm 4322 ;$ \\
& $0.82^{*}$ & $1.93^{*}$ & $0.78^{*}$ & $0.62^{*}$ & $0.63^{*}$ \\
\hline
\end{tabular}

Validation of RP-HPLC/UV Separation and Detection Method

The method was selected because the resolution parameter has met the minimum requirements (Table-4). The value of Rs $\geq 1.5$ indicates the six compounds (GA, TB, TP, CAF, C, and EGCG) separate well and are supported by a chromatogram profile (Fig.-4a). The chromatogram profile shows no overlap at the peak between compounds. The variable used as one of the indicators for evaluating the standard curve equation is $r^{2}$. The six equations obtained have a value of $r^{2}>0.999$ and show a good correlation between curves with the concentration of standard compounds (Table-5 and Fig.-3). The LoD found was 0.13, $0.18,0.26,0.17,0.61$, and $0.75 \mu \mathrm{g} / \mathrm{mL}$, whereas, the LoQ was $0.40,0.54,0.79,0.50,1.82$, and 2.24 $\mu \mathrm{g} / \mathrm{mL}$ for GA, TB, TP, CAF, C, and EGCG, respectively.

Table-5: Validation Parameters on the Method of Separating Several Compounds Simultaneously Using RP-HPLC

\begin{tabular}{c|c|c|c|c|c}
\hline $\begin{array}{c}\text { Active } \\
\text { Ingredient }\end{array}$ & $\begin{array}{c}\text { Concentration } \\
\text { Range }(\mu \mathrm{g} / \mathrm{mL})\end{array}$ & $\begin{array}{c}\text { Calibration Curve } \\
\text { Regression }\end{array}$ & $\begin{array}{c}\text { Correlation } \\
\text { Coefficient }\left(r^{2}\right)\end{array}$ & $\begin{array}{c}\text { LoD } \\
(\mu \mathrm{g} / \mathrm{mL})\end{array}$ & $\begin{array}{c}\text { LoQ } \\
(\mu \mathrm{g} / \mathrm{mL})\end{array}$ \\
\hline Gallic acid & $0.11-9.68$ & $\mathrm{y}=64280 \mathrm{x}-483.57$ & 0.9999 & 0.11 & 0.34 \\
\hline Theobromine & $0.10-9.15$ & $\mathrm{y}=66405 \mathrm{x}+111.68$ & 0.9998 & 0.16 & 0.47 \\
\hline Theophylline & $0.01-9.49$ & $\mathrm{y}=60918 \mathrm{x}-2079.7$ & 0.9996 & 0.26 & 0.79 \\
\hline Catechin & $0.10-9.05$ & $\mathrm{y}=15911 \mathrm{x}-1557.6$ & 0.9998 & 0.16 & 0.49 \\
\hline Caffeine & $1.02-17.13$ & $\mathrm{y}=63648 \mathrm{x}-25303$ & 0.9993 & 0.59 & 1.78 \\
\hline EGCG & $0.99-36.22$ & $\mathrm{y}=26755 \mathrm{x}-16302$ & 0.9998 & 0.56 & 1.69 \\
\hline
\end{tabular}


RASĀYAN J. Chem.

Vol. 12 | No. 3 |1098 - 1109| July - September | 2019

A precision and accuracy study was also carried out; the percent of RSD and recovery are presented in Table-6. The RSD ( $n=3$ ) for GA, TB, TP, C, CAF, and EGCG were within the range of $0.36-3.74 \%$. The results of the separation of the six compounds show a high value of precision and good accuracy of the analysis procedures developed. Percent recovery $(n=3)$ for GA, TB, TP, C, CAF, and EGCG were in the range of $93.54 \pm 2.30-101.99 \pm 0.36$ (mean $\pm \mathrm{SD}$ ). Robustness evaluation is related to the resolution of as the SST, and in this study, the value of Rs must be greater than 1.5. Therefore, acetonitrile and methanol ratios should be maintained at $10 \%$ and the flow rate of $0.90 \mathrm{~mL} / \mathrm{min}$ to meet the SST criteria. Robustness can be evaluated from the predicted normal operation (factors) and the desirability value of the response according to the design. However, the analysis procedure with the developed system has a good response, namely, acetonitrile $10 \%$, methanol $10 \pm 0.15 \%$ and flow rate $0.90 \pm 0.02 \mathrm{~mL} / \mathrm{min}$, according to the optimal conditions in the design space of the method.
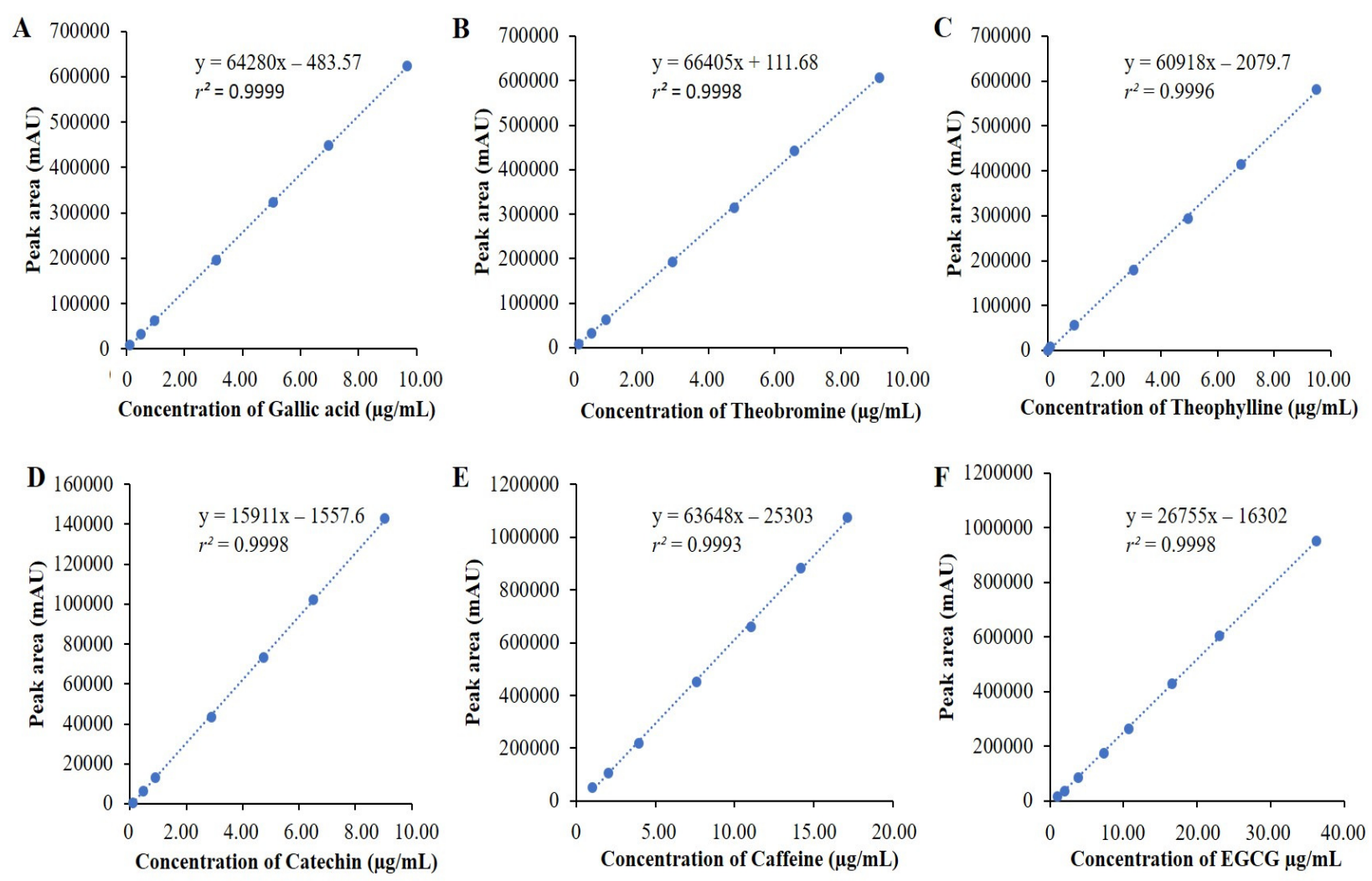

Fig.-2: The Calibration Curve of Each Standard, Gallic Acid (A), Theobromine (B), Theophylline (C), Catechin (D), Caffeine (E), and Epigallocatechin Gallate (F)

\section{Assay of GA, TB, TP, CAF, C, and EGCG in White Tea Extract}

The separation profile of the active compounds in white tea extract samples, as presented in Fig.-4, which indicate good separation and detection. Table-7 shows the results of GA, TB, TP, CAF, C, and EGCG analysis data on samples of white tea extract obtained from several regions in Indonesia. The highest EGCG compound was found in sample 1 with a percentage of $41.27 \pm 0.60 \%$. The percentages of CAF in samples 1,2 , and 3 were $16.80 \pm 0.49 \%, 18.38 \pm 0.29 \%$, and $14.93 \pm 0.26 \%$, respectively. During the analysis of compound $\mathrm{C}$ on sample 2 was not detected.

The chemical structures of GA, TB, TP, CAF, C, and EGCG include chromophores consisting of aromatic rings with conjugate and Auxo chrome systems ${ }^{34}$. Therefore, some of these compounds can absorb electromagnetic radiation in the UV region at wavelengths of 210 and $280 \mathrm{~nm}$. However, a chromatogram with detection set at a wavelength of $210 \mathrm{~nm}$ will have interference due to noise from UV absorption by organic solvents, such as methanol and acetonitrile ${ }^{12,19}$. Therefore, a $280 \mathrm{~nm}$ wavelength was chosen in this study to detect several compounds in chromatographic separation from a sample of white tea leaf extract. 
Differences in process parameters (i.e., the ratio of acetonitrile and methanol, the flow rate, etc.) lead to differences in the effectiveness and efficiency of HPLC methods. ${ }^{22,30,35}$ Therefore, in the present study, CCD was employed to estimate the effects of solvent composition and flow rate on chromatographic separation to obtain an optimal analytical HPLC procedure for alkaloids and phenolics in a white tea leaf extract.

Table-6: Precision and Accuracy of the HPLC-UV Separation and Detection Method

\begin{tabular}{|c|c|c|c|c|c|c|c|}
\hline \multirow[t]{2}{*}{ Compound } & \multirow{2}{*}{$\begin{array}{c}\text { Value } \\
(\mu \mathrm{g} / \mathrm{mL})\end{array}$} & \multicolumn{3}{|c|}{ Intra-Day $(n=3)$} & \multicolumn{3}{|c|}{ Inter-Day $(n=3)$} \\
\hline & & $\begin{array}{c}\text { Mean } \pm \\
\text { SD } \\
(\mu \mathrm{g} / \mathrm{mL})\end{array}$ & $\begin{array}{l}\text { Precision, } \\
\text { RSD (\%) }\end{array}$ & $\begin{array}{l}\text { Accuracy } \\
\pm \text { SD }(\%)\end{array}$ & $\begin{array}{c}\text { Mean } \pm \\
\text { SD } \\
(\mu \mathrm{g} / \mathrm{mL})\end{array}$ & $\begin{array}{l}\text { Precision, } \\
\operatorname{RSD}(\%)\end{array}$ & $\begin{array}{c}\text { Accuracy } \pm \\
\text { SD }(\%)\end{array}$ \\
\hline \multirow[t]{3}{*}{ Gallic acid } & 4 & $\begin{array}{c}4.33 \pm \\
0.01\end{array}$ & 1.88 & $\begin{array}{c}97.89 \pm \\
1.84 \\
\end{array}$ & $\begin{array}{c}4.27 \pm \\
0.001\end{array}$ & 0.18 & $\begin{array}{c}97.08 \pm \\
0.17\end{array}$ \\
\hline & 5 & $\begin{array}{c}5.13 \pm \\
0.01\end{array}$ & 1.36 & $\begin{array}{c}98.34 \pm \\
1.34\end{array}$ & $\begin{array}{l}5.18 \pm \\
0.003\end{array}$ & 0.49 & $\begin{array}{c}97.91 \pm \\
0.48\end{array}$ \\
\hline & 6 & $\begin{array}{c}6.07 \pm \\
0.003\end{array}$ & 0.59 & $\begin{array}{c}98.64 \pm \\
0.58\end{array}$ & $\begin{array}{c}6.07 \pm \\
0.01\end{array}$ & 1.13 & $\begin{array}{c}98.66 \pm \\
1.11\end{array}$ \\
\hline \multirow[t]{3}{*}{ Theobromine } & 4 & $\begin{array}{c}3.86 \pm \\
0.003\end{array}$ & 1.83 & $\begin{array}{c}98.95 \pm \\
1.81\end{array}$ & $\begin{array}{l}3.85 \pm \\
0.003\end{array}$ & 1.75 & $\begin{array}{c}99.78 \pm \\
1.74\end{array}$ \\
\hline & 5 & $\begin{array}{l}4.82 \pm \\
0.002\end{array}$ & 1.41 & $\begin{array}{c}98.76 \pm \\
1.39\end{array}$ & $\begin{array}{l}4.76 \pm \\
0.002\end{array}$ & 1.40 & $\begin{array}{c}98.30 \pm \\
1.38\end{array}$ \\
\hline & 6 & $\begin{array}{l}5.90 \pm \\
0.001\end{array}$ & 0.80 & $\begin{array}{c}96.82 \pm \\
0.78\end{array}$ & $\begin{array}{l}5.87 \pm \\
0.003\end{array}$ & 1.95 & $\begin{array}{c}97.53 \pm \\
1.90\end{array}$ \\
\hline \multirow[t]{3}{*}{ Theophylline } & 4 & $\begin{array}{c}3.82 \pm \\
0.001\end{array}$ & 1.72 & $\begin{array}{c}97.44 \pm \\
1.67\end{array}$ & $\begin{array}{c}3.80 \pm \\
0.001\end{array}$ & 1.28 & $\begin{array}{c}97.62 \pm \\
1.25\end{array}$ \\
\hline & 5 & $\begin{array}{l}4.65 \pm \\
0.001\end{array}$ & 1.44 & $\begin{array}{c}98.41 \pm \\
1.42 \\
\end{array}$ & $\begin{array}{l}4.91 \pm \\
0.001\end{array}$ & 1.37 & $\begin{array}{c}96.12 \pm \\
1.32 \\
\end{array}$ \\
\hline & 6 & $\begin{array}{c}5.75 \pm \\
0.001\end{array}$ & 1.30 & $\begin{array}{c}95.19 \pm \\
1.23\end{array}$ & $\begin{array}{l}5.70 \pm \\
0.001\end{array}$ & 1.42 & $\begin{array}{c}94.67 \pm \\
1.34\end{array}$ \\
\hline \multirow[t]{3}{*}{ Catechin } & 4 & $\begin{array}{l}3.92 \pm \\
0.002\end{array}$ & 0.71 & $\begin{array}{c}96.54 \pm \\
0.69\end{array}$ & $\begin{array}{l}3.88 \pm \\
0.003\end{array}$ & 1.22 & $\begin{array}{c}96.91 \pm \\
1.18\end{array}$ \\
\hline & 5 & $\begin{array}{l}4.66 \pm \\
0.003\end{array}$ & 1.07 & $\begin{array}{c}97.01 \pm \\
1.04\end{array}$ & $\begin{array}{l}4.75 \pm \\
0.003\end{array}$ & 1.35 & $\begin{array}{c}96.90 \pm \\
1.31\end{array}$ \\
\hline & 6 & $\begin{array}{c}5.81 \pm \\
0.01\end{array}$ & 2.01 & $\begin{array}{c}94.71 \pm \\
1.90\end{array}$ & $\begin{array}{l}5.71 \pm \\
0.003\end{array}$ & 1.40 & $\begin{array}{c}94.71 \pm \\
1.32\end{array}$ \\
\hline \multirow[t]{3}{*}{ Caffeine } & 4 & $\begin{array}{c}10.87 \pm \\
0.05\end{array}$ & 0.63 & $\begin{array}{c}98.06 \pm \\
0.62\end{array}$ & $\begin{array}{c}11.01 \pm \\
0.11\end{array}$ & 1.50 & $\begin{array}{c}99.98 \pm \\
1.50\end{array}$ \\
\hline & 5 & $\begin{array}{c}11.73 \pm \\
0.05 \\
\end{array}$ & 0.70 & $\begin{array}{c}100.40 \pm \\
0.71\end{array}$ & $\begin{array}{c}11.68 \pm \\
0.13 \\
\end{array}$ & 1.87 & $\begin{array}{c}97.85 \pm \\
1.83 \\
\end{array}$ \\
\hline & 6 & $\begin{array}{c}12.55 \pm \\
0.03\end{array}$ & 0.42 & $\begin{array}{c}97.89 \pm \\
0.41\end{array}$ & $\begin{array}{c}12.55 \pm \\
0.06\end{array}$ & 0.84 & $\begin{array}{c}97.95 \pm \\
0.82\end{array}$ \\
\hline \multirow[t]{3}{*}{ EGCG } & 4 & $\begin{array}{c}22.49 \pm \\
0.22 \\
\end{array}$ & 1.20 & $\begin{array}{c}98.41 \pm \\
1.18 \\
\end{array}$ & $\begin{array}{c}22.59 \pm \\
0.11 \\
\end{array}$ & 0.61 & $\begin{array}{c}99.33 \pm \\
0.61\end{array}$ \\
\hline & 5 & $\begin{array}{c}23.19 \pm \\
0.15\end{array}$ & 0.80 & $\begin{array}{c}99.78 \pm \\
0.80\end{array}$ & $\begin{array}{c}23.45 \pm \\
0.25\end{array}$ & 1.36 & $\begin{array}{c}99.39 \pm \\
1.35\end{array}$ \\
\hline & 6 & $\begin{array}{c}24.53 \pm \\
0.07\end{array}$ & 0.36 & $\begin{array}{c}101.73 \pm \\
0.36\end{array}$ & $\begin{array}{c}24.64 \pm \\
0.37\end{array}$ & 1.96 & $\begin{array}{c}100.57 \pm \\
1.97\end{array}$ \\
\hline
\end{tabular}

Table-7: The Contents of Gallic Acid, Theobromine, Theophylline, Catechin, Caffeine, and EGCG in White Tea (Camellia sinensis L.) Leaf Extract $(n=6)$

\begin{tabular}{c|c|c|c|c|c|c}
\hline \multirow{2}{*}{ Sample } & \multicolumn{7}{|c}{ Concentration $(\% \mathrm{~b} / \mathrm{b})$} \\
\cline { 2 - 7 } & GA & TB & TP & C & CAF & EGCG \\
\hline Sample 1 & $0.97 \pm 0.01$ & $0.37 \pm 0.02$ & $0.13 \pm 0.002$ & $0.49 \pm 0.01$ & $13.23 \pm 0.32$ & $30.09 \pm 0.37$ \\
\hline Sample 2 & $1.11 \pm 0.02$ & $0.31 \pm 0.01$ & $0.14 \pm 0.003$ & ND & $15.27 \pm 0.66$ & $22.54 \pm 0.41$ \\
\hline Sample 3 & $1.31 \pm 0.05$ & $0.27 \pm 0.01$ & $0.16 \pm 0.01$ & $0.74 \pm 0.03$ & $11.26 \pm 0.40$ & $28.08 \pm 0.21$ \\
\hline
\end{tabular}


A
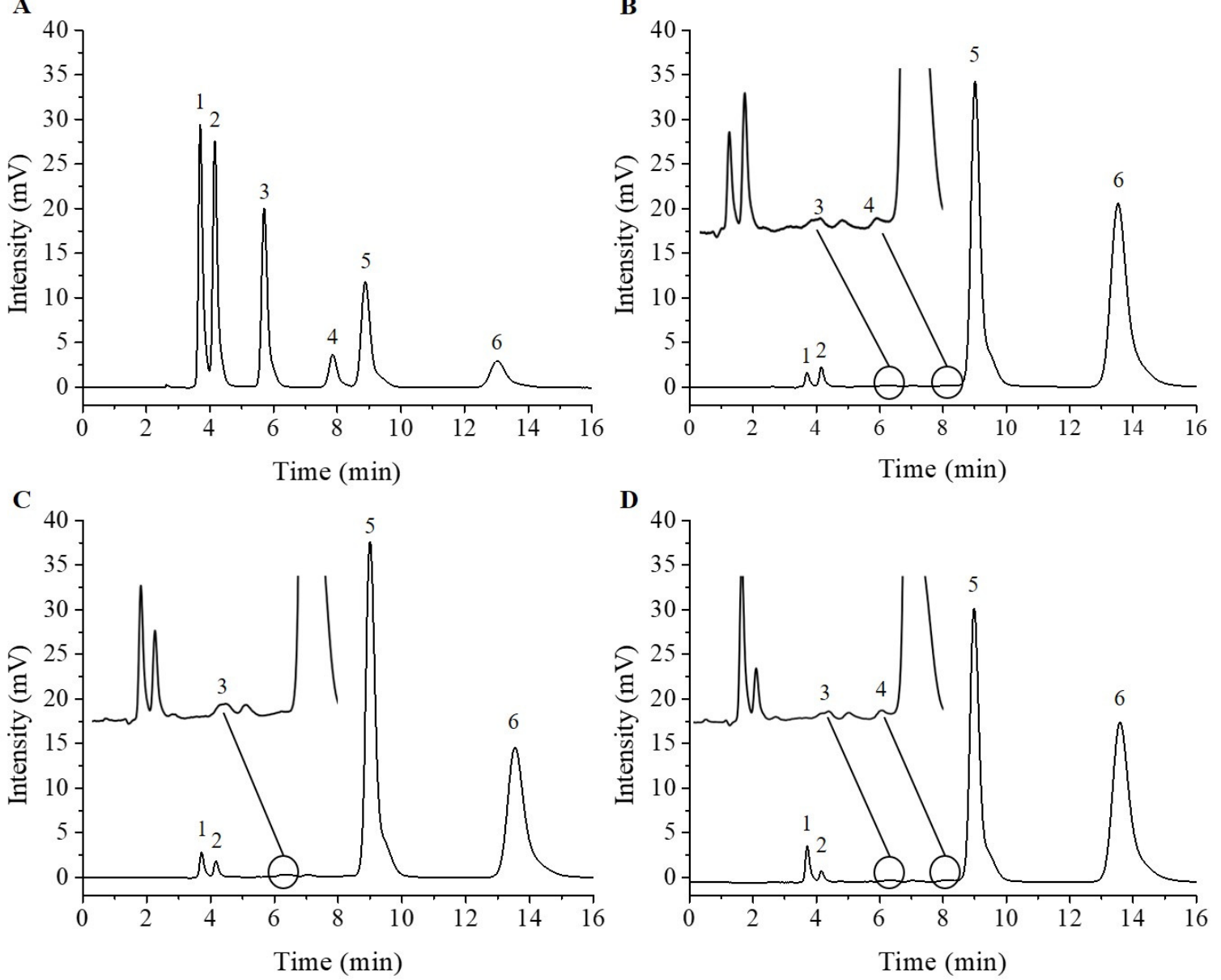

Fig.-4: The Typical HPLC Chromatographic Profile of Six Standards Using Optimized Condition (A) and the Chromatographic Profile of White Tea Extracts from Sample 1 (B), Sample 2 (C), and Sample 3 (D). HPLC Peaks:

1 Gallic Acid; 2 Theobromine; 3 Theophylline; 4 Catechin; 5 Caffeine; 6 Epigallocatechin Gallate

CCD is commonly applied to nonlinear responses and can be used to optimize the separation of several compounds on HPLC systems by elucidating the main factors and their interaction effects. ${ }^{21,36}$

The HPLC system at optimum conditions meets the system suitability test. The validation parameters specified refer to the guidelines established by the International Council for Harmonization of Technical Requirements for Pharmaceuticals for Human Use Q2(R1) guidelines ${ }^{29}$. Determining several validation parameters, namely selectivity, linearity, the limit of detection (LoD), the limit of quantification (LoQ), precision, and accuracy. Selectivity, sensitivity, and linearity in the developed method have good results as required. This method also has strong accuracy and precision. Robustness is an indicator of the analytical method not to be affected by slight changes, for example, deliberate variations created in the parameters of the analysis method ${ }^{22,31}$.

Validation results on optimal conditions of RP-HPLC/UV instrumentation were used in the separation, detection, and quantification of GA, TB, TP, CAF, C, and EGCG in the white tea extract. The three samples showed varying GA, TB, TP, C, CAF, and EGCG data due to the influence of the plant origin (e.g., climate, soil conditions, rainfall). Active ingredient separation using basic HPLC for detection and quantification of compounds in tea such as HPLC-ECD ${ }^{14}$, HPLC-MS-MS ${ }^{37}$, UPLC ${ }^{38}$, Nano HPLC ${ }^{39}$, UFLC-MS/MS ${ }^{15}$, and UPLC-Q-TOF/MS ${ }^{16}$ were also developed. The HPLC-MS, UFLC-MS/MS or UPLC-Q-TOF/MS methods generally have high sensitivity and suitable for plasma analysis. However, for the purposes of routine analysis on extract samples, the system is expensive and requires special technical expertise ${ }^{19,20}$. In this case, routine analysis methods for laboratory and industrial extracts, are less suitable. The results of modification, HPLC system optimization with UV detector and method 
validation can be applied to analyze the gallic acid, theobromine, theophylline, catechin, caffeine, and EGCG simultaneously in white tea extract samples.

\section{CONCLUSION}

The HPLC method developed here is simple, easy, fast, and precise to measure gallic acid, theobromine, theophylline, catechin, caffeine, and EGCG levels from white tea extract products. The approach with DoE and CCD was effectively used for optimizing the separation of six compounds from white tea extract. The developed method is suitable for the analysis of the quality control sample extract. Simple isocratic HPLC systems, easy preparation, and quick analysis make it more suitable for the daily procedures in the food, phytopharmaceutical or extracting industries and quality control laboratories.

\section{ACKNOWLEDGMENT}

The authors gratefully acknowledge the financial support by Beasiswa Unggulan Dosen Indonesia Dalam Negeri (BUDI DN) No. 20161141040054 and Lembaga Pengelola Dana Pendidikan (LPDP) Indonesia.

\section{REFERENCES}

1. T. Tounekti, E. Joubert, I. Hernández and S. Munné-Bosch, Crit. Rev. Plant Sci., 32, 192(2013), DOI: $10.1080 / 07352689.2012 .747384$.

2. I. Sopyan, R. D. Permata, D. Gozali and I. S. K. Syah, Int. J. Appl. Pharm. 11, 205(2019), DOI: 10.22159/ijap.2019v11i1.29564.

3. A. Gramza-Michałowska, J. Nutr. Health Aging, 18, 143(2014), DOI: 10.1007/s12603-013-0404-1.

4. S. Shiyan, Herlina, M. Bella and A. Amriani, Pharmaciana, 7, 278(2017), DOI: 10.12928/pharmaciana.v7i2.6622

5. E. Damiani, T. Bacchetti, L. Padella, L. Tiano and P. Carloni, J. Food Compos. Anal., 33, 59 (2014), DOI: $10.1016 /$ j.jfca.2013.09.010.

6. G. C. Tenore, P. Stiuso, P. Campiglia and E. Novellino, Food Chem., 141, 2379(2013), DOI: 10.1016/j.foodchem.2013.04.128.

7. M. S. Islam, Phytomedicine, 19, 25(2011), DOI: 10.1016/j.phymed.2011.06.025.

8. M. P. Almajano, I. Vila and S. Gines, Neurotox. Res., 20, 372(2011), DOI: 10.1007/s12640-0119252-0.

9. W. J. Yen, C. C. Chyau, P. U. Lee, H. L. Chu, L. W. Chang and P. D. Duh, Food Chem., 141, 4107(2013), DOI: 10.1016/j.foodchem.2013.06.106.

10. D. Kumar, A. Gulati and U. Sharma, Food Anal. Methods, 9, 1666(2016), DOI: 10.1007/s12161015-0343-Z.

11. A. de Villiers, P. Venter and H. Pasch, H. J. Chromatogr. A, 1430, 16(2016), DOI: 10.1016/j.chroma.2015.11.077.

12. E. Susanti, Ciptati, R. Ratnawati, Aulanni'am and A. Rudijanto, Asian Pac. J. Trop. Biomed., 5, 1046(2015), DOI: 10.1016/j.apjtb.2015.09.013.

13. A. A. Rahim, S. Nofrizal and B. Saad, Food Chem., 147, 262(2014), DOI: 10.1016/j.foodchem.2013.09.131.

14. I. Novak, M. Šeruga and Š. Komorsky-Lovrić, Food Chem., 122, 1283(2010), DOI: 10.1016/j.foodchem.2010.03.084.

15. Y. Huo, Q. Zhang, Q. Li, B. Geng and K. Bi, J. Pharm. Biomed. Anal., 125, 229(2016), DOI: 0.1016/j.jpba.2016.03.048.

16. J. Jing, Y. Shi, Q. Zhang, J. Wang and J. Ruan, Food Chem., 221, 311(2017), DOI: 10.1016/j.foodchem.2016.10.068.

17. J. Cai, Y. Wang, X. Xi, H. Li and X. Wei, Int. J. Biol. Macromol., 78, 439(2015), DOI: 10.1016/j.ijbiomac.2015.03.025.

18. A. Ricci, K. J. Olejar, G. P. Parpinello, P. A. Kilmartin and A. Versari, Appl. Spectrosc. Rev., 50, 407(2015), DOI: $10.1080 / 05704928.2014 .1000461$.

19. C. D. Fernando and P. Soysa, Springerplus 5, (2016), DOI: 10.1186/s40064-016-2672-9. 
RASĀYAN J. Chem.

Vol. 12 | No. 3 |1098 - 1109| July - September | 2019

20. A. Y. Yashin, B. V. Nemzer, E. Combet and Y. I. Yashin, J. Food Res. 4, 56(2015), DOI: 10.5539/jfr.v4n3p56.

21. A. Mittal, S. S. Imam, S. Parmar, S. J. Gilani and M. Taleuzzaman, Austin J. Anal. Pharm. Chem., 2, 1057(2015).

22. P. K. Sahu, N. R. Ramisetti, T. Cecchi, S. Swain, C. S. Patro and J. Panda, J. Pharm. Biomed. Anal., 147, 590(2018), DOI: 10.1016/j.jpba.2017.05.006.

23. N. K. Prabaningdyah, S. Riyanto, A. Rohman and C. Siregar, J. App. Pharm. Sci., 7, 58(2017), DOI: 10.7324/JAPS.2017.71207.

24. I. K. Bae, H. M. Ham, M. H. Jeong, D. H. Kim and H. J. Kim, Food Chem., 172, 469(2015), DOI: 10.1016/j.foodchem.2014.09.050.

25. A. A. F. Zielinski, C. W. I. Haminiuk and T. Beta, LWT-Food Sci. Technol. 65, 897(2016), DOI: 10.1016/j.lwt.2015.09.020.

26. J. Mamatha and N. Devanna, Rasayan J. Chem., 11, 392(2018), DOI: 10.7324/RJC.2018.1111931.

27. A. G. González and M. A. Herrador, TrAC, Trends Anal. Chem., 26, 227(2007), DOI: 10.1016/j.trac.2007.01.009.

28. O. Indrati, R. Martien, A. Rohman and A. K. Nugroho, Int. J. Appl. Pharm., 10, 135(2018), DOI: 10.22159/ijap.2018v10i6.28691

29. ICH. Validation of Analytical Procedures: Text And Methodology. (2005).

30. J. Rani and N. Devanna, Rasayan J. Chem., 11, 452(2018), DOI: 10.31788/RJC.2018.1122079.

31. M. V. Murthy, C. Krishnaiah, K. Srinivas, K. S. Rao, N. R. Kumar and K. Mukkanti, J. Pharm. Biomed. Anal., 72, 40(2013), DOI: 10.1016/j.jpba.2012.09.013.

32. S. Shiyan, T. Hertiani, R. Martien and A. K. Nugroho, Int. J. Appl. Pharm., 10, 259(2018), DOI: 10.22159/ijap.2018v10i6.29654.

33. G. Pratiwi, R. Martien and R. Murwanti, Int. J. Appl. Pharm., 11, 50(2019), DOI: 10.22159/ijap.2019v11i2.29999.

34. S. T. Saito, A. Welzel, E. S. Suyenaga and F. Bueno, Food Sci. Technol., 26, 394(2006), DOI: 10.1590/S0101-20612006000200023.

35. J. Mamatha and N. Devanna, Rasayan J. Chem., 11, 300(2018), DOI: 10.7324/RJC.2018.1112007.

36. A. Rahmani, J. Selamat and F. Soleimany, Food Additives and Contaminants: Part A, 28, 902(2011), DOI: $10.1080 / 19440049.2011 .576436$.

37. W. Tao, Z. Zhou, B. Zhao and T. Wei, J. Pharm. Biomed. Anal., 131, 140(2016), DOI: 10.1016/j.jpba.2016.08.020.

38. H. Jiang, U. H. Engelhardt, C. Thräne, B. Maiwald and J. Stark, Food Chem., 183, 30(2015), DOI: 10.1016/j.foodchem.2015.03.024.

39. C. Fanali, A. Rocco, Z. Aturki, L. Mondello and S. Fanali, J. Chromatogr. A., 1234, 38(2012), DOI: 10.1016/j.chroma.2011.12.103.

[RJC-5276/2019] 